\title{
MENGENAL FINTECH \\ SEBAGAI INOVASI BISNIS KEUANGAN
}

\author{
Agung Purnomo \\ Institut Teknologi Kreatif Bina Nusantara Malang \\ agung.purnomo@binus.ac.id
}

\section{Mengenal Fintech}

Financial Technology atau teknologi keuangan, saat ini lebih dikenal dengan istilah 'fintech' dapat didefinisikan sebagai program komputer dan teknologi lainnya yang digunakan untuk mendukung atau mengaktifkan perbankan dan jasa keuangan (1). Fintech adalah bisnis yang bertujuan menyediakan jasa keuangan dengan memanfaatkan perangkat lunak dan teknologi modern (2). Fintech adalah kombinasi dari teknologi keuangan yang menggambarkan sektor jasa keuangan yang muncul di abad ke-21. Awalnya, istilah yang diterapkan untuk teknologi diterapkan pada back-end dari konsumen yang didirikan dan perdagangan lembaga keuangan. Sejak akhir dekade pertama abad ke-21, istilah ini telah diperluas untuk mencakup inovasi teknologi di sektor keuangan, termasuk inovasi dalam pendidikan dan kecerdasan finansial, perbankan ritel, investasi dan bahkan mata uang kripto seperti bitcoin (3).

Fintech adalah industri ekonomi yang terdiri dari perusahaan yang menggunakan teknologi untuk membuat jasa keuangan agar lebih efisien. Sungguh cukup sulit untuk mendefinisikan konsep Fintech, karena definisi berubah dari waktu ke waktu. Juga karena organisasi perbankan tradisional terhalang berkembang akibat warisan sistem operasional, kapasitas untuk berinovasi, kelincahan dan keahlian teknologi. Fintech umumnya merupakan bisnis startup yang didirikan dengan tujuan mengganggu sistem dan perusahaan keuangan yang ada namun kurang mengandalkan dan mengoptimalkan penggunaan teknologi software (4). 


\section{Jenis Fintech}

FinTech di Indonesia memiliki beberapa ragam, antara lain startup pembayaran, riset keuangan, investasi ritel, pembiayaan (lending \& crowdfunding), perencanaan keuangan (personal finance), dan remitansi. Berikut ini daftar beberapa perusahaan startup bisnis FinTech di Indonesia (5), yaitu:

\section{A. Pembayaran (Payments)}

- Perusahaan pembayaran: Veritrans, DoKu, Kartuku, iPay88, Easypay, MCpayment, Padipay, Kinerjapay.com, Truemoney, Faspay, Fasapay, Xendit, Espay, Wallezz, Cashlez, Mimopay, Indopay, Firstpay, IPaymu.com, Ovo, Nicepay, Hellopay, Kesles,

- Mobile payments company: Sakuku BCA, Dompetku Indosat Ooredoo, Uangku SmartFren, Dimo, Mynt, Matchmove.

- Gift Card: GCI Indonesia.

- BitCoin: BitX.co.

- Electronic Money: Sepulsa.com, Davestpay.com, GoPay, Indomog, Kudo, Ayopop.

- Bebas Transfer: Kliring.co.id, SudahTransfer, Flip.

- Bayar Tagihan: Paybill.id, SatuLoket.com.

- Lainnya: Ainosi.

\section{B. Riset Keuangan}

\section{Investasi}

- Bareksa dan IpotFund.

\section{D.Pembiayaan (Lending)}

- Pembiayaan berbentuk utang: UangTeman.com, TemanUsaha.com, Terhubung.com, BosTunai.com, Mekar.id, Tanihub.com, Taralite.com, Pinjam.co.id, Eragano.com, DrRupiah.com. 
- Pembiayaan berbasis patungan atau pembiayaan masal (crowdfunding): Wujudkan.com, Kitabisa.com, Ayopeduli.com dan GandengTangan.org. WeCare.id, Indves.com, GandengTangan.org, LimaKilo.id, iGrow.asia, Iwak.me, KapitalBoost.com

- Pembiayaan berbasis Peer to Peer Lending (P2P): Koinworks.com, Amartha.com, DanaDidik.com, Crowdo.com, Investree.com.

- Cicilan Tanpa Kartu Kredit: Kredivo.com, ShootYourDream.com, Cicil.co.id.

\section{E. Perencanaan Keuangan}

\section{F.Situs Pembanding Produk Keuangan (Comparison Site atau Financial Aggregator)}

- Produk Keuangan secara umum: DuitPintar.com, HaloMoney.co.id, CekAja.com, Cermati.com, PilihPintar.co.id, SikatAbis.com, AturDuit.com, KreditGoGo.com.

- Khusus Asuransi: RajaPremi.com, Asuransi88.com, PremiKita.com, Premiro.com, PasarPolis.com, CekPremi.com.

\section{Penutup}

Demikian tentang Fintech sebagai inovasi bisnis keuangan beserta pengembangannya di Indonesia. 


\section{References}

1. Oxford Dictionaries. Fintech [Internet]. oxforddictionaries.com. 2017 [cited 2017 Mar 28]. Available from:

https://en.oxforddictionaries.com/definition/fintech

2. Fintech Weekly. Fintech Definition [Internet]. Fintechweekly.com. 2017 [cited 2017 Mar 29]. Available from: https://fintechweekly.com/fintechdefinition

3. Investopedia. Fintech [Internet]. investopedia.com. 2017 [cited 2017 Mar 30]. Available from: http://www.investopedia.com/terms/f/fintech.asp

4. Sharma V. What is FinTech and where does it Live?. [Internet]. finextra.com. 2016 [cited 2017 Mar 29]. Available from: https://www.finextra.com/blogposting/12890/what-is-fintech-and-wheredoes-it-live

5. Finansialku. Apa Itu Industri Financial Technology (FinTech Indonesia) [Internet]. Finansialku.com. 2016 [cited 2017 Mar 30]. Available from: https://www.finansialku.com/apa-itu-industri-financial-technologyfintech-indonesia/ 